\title{
Self-reported medication adherence to antiepileptic drugs and treatment satisfaction among paediatric patients having epilepsy: A cross sectional study from the Indian subcontinent
}

\author{
Sandhya Chauhan ${ }^{1}$, Prem Lochan Prasad ${ }^{1}$, Bhawana Khurana ${ }^{1}$, *Pratik Gahalaut ${ }^{1}$
}

Sri Lanka Journal of Child Health, 2018; 47(2): 129-136

\begin{abstract}
Introduction: Non adherence to antiepileptic drugs (AEDs) can vary the course of epilepsy. There is a dearth of data regarding adherence status among paediatric epilepsy patients.
\end{abstract}

Objectives: To determine the level of AED adherence among paediatric patients having epilepsy and to assess the relationship between AED adherence and treatment satisfaction among paediatric epileptics.

Method: A cross sectional study was conducted at a tertiary level referral hospital in northern India from July 2015 to June 2016 on children aged 2 to 13 years of age, diagnosed with epilepsy and treatment initiated with at least 1 AED for the past 6 months. Data collection was done using a questionnaire which was divided into three parts. The first part comprised demographical information about patients and their caregivers along with clinical details of epilepsy. The second part gathered information about medication adherence profile with the help of the Morisky Medication Adherence Scale-8 (MMAS-8). The third part gathered data on treatment satisfaction profile about these patients with the help of Treatment Satisfaction Questionnaire for Medication (TSQM 1.4). The estimated sample size was at least 61 patients. Data was analysed using Graph Pad InStat 6.0. Ethical approval was obtained from the institutional ethics committee.

Results: A convenient sample of 112 patients with their respective immediate caregivers was enrolled in this study. The mean age of children was $9.82 \pm 2.17$ years and male to female sex ratio was 1.24 . Fifty $(44.6 \%)$ patients had low adherence, 29 (25.9\%) medium adherence and 33 (29.5\%) high

\footnotetext{
${ }^{1}$ Shri Ram Murti Smarak Institute of Medical Sciences, India

*Correspondence: drpratikg@rediffmail.com

(Received on 02 June 2017: Accepted after revision on 28 July 2017)

The authors declare that there are no conflicts of interest

Personal funding was used for the project.

Open Access Article published under the Creative

Commons Attribution CC-BY (CC)
}

adherence to AEDs as per MMAS-8 questionnaire. Altogether 79 (70.5\%) children were non adherent when dichotomised MMAS scores were considered. Age of children, duration of epilepsy, mean number of family members, frequency of drug ingestion by patient, employment status of caregiver were significantly associated with nonadherence in epileptic children. Children adhering to medication prescription had significantly higher satisfaction in the effectiveness, convenience and global satisfaction domains of TSQM.

Conclusions: Twenty nine percent of epileptic children showed medication adherence to AEDs in the present study. Increasing age of children, increased duration of epilepsy, increasing mean number of family members, patients taking medications more than once per day and employed caregiver status were significantly associated with non-adherence in epileptic children. Satisfaction scores were higher in medication adherent children, particularly in the effectiveness, convenience and global satisfaction domains but not in the side effects domain.

DOI: http://dx.doi.org/10.4038/sljch.v47i2.8478

(Key words: Medication compliance, antiepileptic drugs, children, epilepsy)

\section{Introduction}

In India, prevalence of children with epilepsy varies from 2 to 22 per $1,000^{1}$. However, there is a significant treatment gap, especially in low income countries $^{2}$. Non adherence to antiepileptic drugs (AEDs) has been reported among $55 \%$ of paediatric and $70 \%$ of adult patients ${ }^{3}$. Improving paediatric adherence to treatment is especially important as there is evidence that complying with treatment improves the health outcomes of children more than that of adults ${ }^{4}$. AED adherence can be measured by self-reporting, drug level monitoring or prescription refill monitoring ${ }^{5}$. Treatment satisfaction can affect a patient's health-related decision making ${ }^{5}$. Measures have been developed for assessing treatment satisfaction ${ }^{6,7}$. A review of the literature did not reveal any studies from the Indian subcontinent which measured the relationship between adherence to drug treatment and treatment satisfaction among paediatric epileptic patients. 


\section{Objectives}

To determine the level of AED adherence among paediatric patients having epilepsy and to assess the relationship between AED adherence and treatment satisfaction among paediatric epileptics.

\section{Method}

A cross sectional descriptive study was conducted from July 2015 to June 2016 in the paediatric outpatient department of a tertiary level care teaching hospital in northern India on children aged 2 to 13 years of age, diagnosed with epilepsy and treatment initiated with at least 1 AED for past 6 months. Approval was obtained from the institutional ethics committee for this study. Data was collected from the primary caregiver of epileptic children. The following inclusion/ exclusion criteria were used:

- Absence of developmental disorders or comorbid chronic illnesses in children requiring daily medications.

- Absence of any other sibling or another family member afflicted by chronic diseases or epilepsy which entails daily administration of drugs.

- Caregiver willing to give informed verbal consent for inclusion in the study.

- The respondent had to be literate and able to read and write Hindi, the local language.

- The child should be having normal neurological and cognitive development.

Age selection was based on the expectation that by the age of 13 years self-care responsibilities would be assumed by adolescents and hence the role of the primary care-giver will diminish. Epilepsy was arbitrarily defined as "well controlled" if the patient reported no seizures in the last 3 months and was defined as "poorly controlled" if they reported having had at least one seizure in the last 3 months ${ }^{5}$.

Data collection was done by the principal investigator in face to face interviews of immediate/principal caregiver of paediatric patients. The questionnaire was divided into three parts. The first part comprised demographical information about patients and their caregivers along with clinical details of epilepsy. The second part gathered information about medication adherence profile with the aid of the Morisky Medication Adherence Scale-8 (MMAS-8). The third part gathered data on treatment satisfaction profile about these patients with the aid of TSQM
1.4 whose Hindi version was obtained from Quintiles Transnational Corp, North Carolina, USA.

MMAS-8 is a structured self-report measure of medication-taking behaviour originally developed for hypertensive patients ${ }^{8}$. It is an 8-item questionnaire with seven yes/no questions and one question answered on a 5-point Likert scale. According to the scoring system for the MMAS, $8=$ high adherence, 6 to $<8=$ medium adherence, and $<6=$ low adherence. Patients who had a low or a moderate rate of adherence were considered nonadherent ${ }^{5}$. MMAS-8 questionnaire has been translated and used for various diseases in Japan?. Though it has been translated into many Asian languages, translated versions in Indian languages are not available in the literature ${ }^{10}$. Hence it was translated into Hindi as explained elsewhere ${ }^{10}$. Two translators, whose native language was Hindi and who were well versed in English, independently translated the English MMAS-8 to Hindi. Another bilingual translator, well versed in both Hindi and English, and who was not involved in developing the initial version, performed reverse translation from Hindi to English. The original and the backtranslated English versions were compared and inconsistencies were resolved by consensus. A pilot test was performed in 10 subjects to ensure correct understanding of the wording of the Hindi version and no inconsistencies were revealed. Cronbach's alpha value of the translated Hindi questionnaire for children with epilepsy was 0.84 in this preliminary study. The subjects who participated in this pilot study phase were not included in the study.

Treatment satisfaction was tested using the Hindi version of the Treatment Satisfaction Questionnaire for Medication (TSQM 1.4) which was obtained by the principal researcher from Quintiles Transnational Corp, USA. The TSQM 1.4 is a 14item psychometrically robust and validated instrument comprising four domains: Effectiveness (questions 1-3), side effects (questions 4-8), convenience (questions 9-11), and global satisfaction (questions 12-14). The TSQM 1.4 domain scores were calculated as recommended by the instrument's authors and described in detail elsewhere ${ }^{6,11,12}$. TSQM 1.4 domain scores range from 0 to 100 , with higher scores representing higher satisfaction in that domain. TSQM provides a unique opportunity to compare various medications used to treat a particular illness on the three primary dimensions of treatment satisfaction (effectiveness, side effects, convenience), as well as patients' overall rating of global satisfaction based on the relative importance of these primary dimensions to patients ${ }^{7}$. 
Sample size: This was calculated based on a reported adherence of approximately $50 \%$ as explained elsewhere 5 . With $\mathrm{z}=1.96$ for a $95 \%$ confidence interval and a total width of confidence interval of $25 \%$, the estimated sample size explained elsewhere was at least 61 patients $^{5}$.

Data analysis: Graph Pad InStat 6.0 was used for data analysis. Qualitative variables were expressed as frequency and percentages and continuous variables were expressed as mean \pm standard deviations. Fisher's exact test was used for determining factors associated with adherence.
Student t-test was used for comparing two groups. Pearson correlation was used for multivariate analysis. The conventional 5\% significance level was used throughout the study.

\section{Results}

From a total convenience sample of 150 patients who were clinically examined during the study period, only 132 patients fulfilled the inclusion criteria. Of these only 112 patients agreed to participate in the study, a response rate of $85 \%$. Gender-wise characteristics of the study population are shown in Table 1.

Table 1: Gender-wise characteristics of the study population

\begin{tabular}{|l|c|c|c|c|}
\hline \multicolumn{1}{|c|}{ Characteristic } & Total & Male & Female & $p$ value \\
\hline Number of patients (\%) & $112(100)$ & $62(55.4)$ & $50(44.6)$ & \\
\hline Mean age in years (SD) & $9.82(2.17)$ & $9.93(1.89)$ & $9.46(2.01)$ & 0.206 (t-test) \\
\hline Mean duration of epilepsy in years (SD) & $3.50(2.00)$ & $3.73(1.99)$ & $03.05(2.01)$ & $0.076(\mathrm{t}$-test) \\
\hline Mean number of family members (SD) & $5.38(1.74)$ & $5.55(1.85)$ & $5.01(1.65)$ & 0.110 (t-test) \\
\hline Number of adherents (\%) & $33(100)$ & $20(60.6)$ & $13(39.4)$ & 0.535 (Fisher's) \\
\hline Number of non-adherents (\%) & $79(100)$ & $42(53.2)$ & $37(46.8)$ & \\
\hline Seizure frequency (\%) & & & & \\
$<1 / 3$ months & $58(51.8)$ & $35(60.3 \%)$ & $23(39.7)$ & 0.342 (Fisher's) \\
$\geq 1 / 3$ months & $54(48.2)$ & $27(50.0 \%)$ & $27(50.0)$ & \\
\hline
\end{tabular}

Male to female sex ratio was 1.24: 1 . The aetiology of epilepsy was specified in $38(33.9 \%)$ and idiopathic in 74 (66.1\%). Epilepsy was generalized in $81.3 \%$, partial in $09.8 \%$ and unclassified in $08.9 \%$. Seventy four $(66.1 \%)$ patients were prescribed mono-drug therapy, $30(26.8 \%)$ used at least 2 AEDs and $08(07.1 \%)$ used more than 2 AEDs. Valproic acid was the most commonly prescribed drug followed by carbamazepine and levetiracetam. Altogether $52 \quad(46.4 \%)$ were prescribed drugs to be taken once a day (even if multi-drugs were used) and $60(53.6 \%)$ were taking drugs more than once a day. Epilepsy was well controlled in $58(51.8 \%)$ patients. Fifty four $(48.2 \%)$ patients had at least 1 seizure in the last 3 months before presentation. No statistically significant differences were found between boys and girls in the study group regarding their age, duration of epilepsy, number of family members, seizure frequency or adherence rates as shown in Table 1.
Mean MMAS score was 5.712 \pm 1.633 and median score of 6 was representative of medium adherence. Fifty (44.6\%) patients had low adherence, 29 (25.9\%) had medium adherence and 33 (29.5\%) had high adherence to antiepileptic medications. Hence, altogether 79 (70.5\%) children were non adherent when dichotomised MMAS scores were considered. Only $33(29.5 \%)$ were adherent to medication. There was a significant and positive correlation between non-adherence and family history of epilepsy ( $p=0.001, r=0.4$ ). Rate of nonadherence increased significantly with an increase in mean number of family members $(p=0.025$, $\mathrm{r}=0.5$ ). Other factors (Table 2) significantly affecting adherence adversely were increasing age, higher duration of epilepsy, family history of epilepsy, increasing family size (more than 5 persons in a family), history of at least 1 seizure in the last 3 months, frequency of drug usage more than once a day and employment status of the caregiver. 
Table 2: Analysis of different variables with adherence levels among study group

\begin{tabular}{|c|c|c|c|}
\hline Characteristic & $\begin{array}{c}\text { Adherent } \\
\text { patients }(n=33)\end{array}$ & $\begin{array}{c}\text { Non adherent } \\
\text { patients }(n=79)\end{array}$ & P value \\
\hline Number of subjects (Total $n=112$ ) & $33(29.5 \%)$ & $79(70.5 \%)$ & \\
\hline Number of males $(\mathrm{n}=62)$ & $20(32.3 \%)$ & $42(67.7 \%)$ & 0.5350 (Fisher's) \\
\hline Number of females $(n=50)$ & $13(26.0 \%)$ & $37(74.0 \%)$ & \\
\hline Mean age in years (SD) & $8.12(3.51)$ & $9.93(1.60)$ & 0.0003 (t-test) \\
\hline Patients with monotherapy [n (\%)] & $20(60.6 \%)$ & $54(68.4 \%)$ & 0.5125 (Fisher's) \\
\hline Patients with polypharmacy [n (\%)] & $13(39.4 \%)$ & $25(31.7 \%)$ & \\
\hline Cause of epilepsy & & & \\
\hline Idiopathic $(\mathrm{n}=74)$ & $22(29.7 \%)$ & $52(70.3 \%)$ & 1.0000 (Fisher's) \\
\hline Specified $(n=38)$ & $11(29.0 \%)$ & $27(71.1 \%)$ & \\
\hline $\begin{array}{l}\text { Duration of epilepsy } \\
\text { (Total }=3.50 \pm 2.00 \text { years) }\end{array}$ & $2.76 \pm 2.05$ & $3.85 \pm 1.88$ & 0.0075 (t-test) \\
\hline Family history of epilepsy present $(n=65)$ & $14(21.5 \%)$ & $51(78.5 \%)$ & 0.0370 (Fisher's) \\
\hline Family size $(>5 / \leq 5)$ & $12 / 21$ & $46 / 33$ & 0.0401 \\
\hline $\begin{array}{l}\text { Mean number of family members [n (SD) }\} \\
{[\text { Total }=5.38(1.74)]}\end{array}$ & $5.76(0.86)$ & $5.11(1.83)$ & 0.0118 (t-test) \\
\hline $\begin{array}{l}\text { Number of patients taking all medications } \\
\text { a. Same time once a day }(n=52) \\
\text { b. More than once a day }(n=60)\end{array}$ & $\begin{array}{l}21(40.4 \%) \\
12(20.0 \%)\end{array}$ & $\begin{array}{l}31(59.6 \%) \\
48(80.0 \%)\end{array}$ & 0.0228 (Fisher's) \\
\hline $\begin{array}{l}\text { Seizure frequency } \\
<1 / 3 \text { months }[\text { Total }=58(51.78 \%)] \\
\geq 1 / 3 \text { months }[\text { Total }=54(48.21 \%)]\end{array}$ & $\begin{array}{l}18(31.0 \%) \\
15(27.8 \%)\end{array}$ & $\begin{array}{l}40(69.0 \%) \\
39(72.2 \%)\end{array}$ & 0.8360(Fisher's) \\
\hline $\begin{array}{l}\text { Employment status of caregiver } \\
\text { Employed }(\mathrm{n}=24) \\
\text { Unemployed }(\mathrm{n}=88)\end{array}$ & $\begin{array}{c}3(12.5 \%) \\
30(34.1 \%)\end{array}$ & $\begin{array}{l}21(87.5 \%) \\
58(65.9 \%)\end{array}$ & 0.0452 (Fisher's) \\
\hline
\end{tabular}

The average TSQM satisfaction scores in the domains of effectiveness, side effects, convenience, and global satisfaction were $65.8 \pm 6.8,53.1 \pm 10.8$, $71.7 \pm 7.4$, and $64.1 \pm 7.3$, respectively. Analysis of satisfaction scores based on adherence levels is shown in Table 3. Patients who were adherent had significantly more mean scores in the effectiveness and convenience domains of TSQM.

Table 3: Satisfaction scores in different domains among study patients

\begin{tabular}{|l|l|c|c|c|}
\hline S no & \multicolumn{1}{|c|}{ TSQM domains } & Adherent patients $(\boldsymbol{n}=33)$ & Non adherent patients $(\boldsymbol{n}=\mathbf{7 9})$ & $\boldsymbol{p}$ value \\
\hline 1. & Effectiveness $( \pm$ SD) & $68.8 \pm 8.8$ & $63.1 \pm 5.9$ & 0.0001 \\
\hline 2 & Side effects $( \pm$ SD) & $54.7 \pm 11.5$ & $50.8 \pm 10.3$ & 0.0804 \\
\hline 3 & Convenience $( \pm$ SD) & $75.6 \pm 3.9$ & $68.7 \pm 8.6$ & 0.0001 \\
\hline 4 & Global satisfaction $( \pm$ SD) & $65.4 \pm 8.2$ & $61.7 \pm 6.8$ & 0.0152 \\
\hline
\end{tabular}

TSQM: Treatment Satisfaction Questionnaire for Medication

\section{Discussion}

To the best of our knowledge, the relationship between medication adherence and treatment satisfaction among paediatric epileptic patients has not been reported before from the Indian subcontinent. Epidemiological data from India shows a higher prevalence of epilepsy among males as compared to females ${ }^{13}$. Mani et $a l^{14}$ and Banerjee $e t a l^{15}$ have reported a peak incidence of epilepsy during early childhood and/or first decade of life. According to Indian community based clinical surveys, most epilepsies are idiopathic or cryptogenic $^{16}$. Udani $\mathrm{V}$ also suggested that more than half of children had symptomatic or cryptogenic localization related epilepsies ${ }^{16}$. AsadiPooya $\mathrm{AA}^{17}$ from Iran reported idiopathic epilepsy in $78.5 \%$ of paediatric and adolescent epileptics, which is similar to our present findings. Udani $\mathrm{V}$ found that generalised epilepsy was twice as common as partial epilepsies ${ }^{16}$. In the present study, too, the majority of children had generalized epilepsy. Similar data was also reported by AsadiPooya $\mathrm{AA}^{17}$.

The most commonly prescribed drug in the paediatric age group is sodium valproate, according to a single centre study conducted by Bhatt et al in India $^{18}$. Another study from India reported the treatment of focal seizures mainly with carbamazepine in children ${ }^{19}$. Valproate is the most common drug reported for generalized tonic-clonic seizures in few recent studies from India ${ }^{20}$. Majority of paediatric patients were prescribed a single AED in past studies, from India and elsewhere, just like the findings of the present study ${ }^{17,20}$. A positive family history was seen in 
more than half our patients. A population-based, case control study in India reported family history of the epilepsy as a strong independent predictor of epilepsy ${ }^{13}$.

Less than $1 / 3^{\text {rd }}(29.45 \%)$ of children reported 'high' adherence in the present study and more than $2 / 3^{\text {rd }}$ $(70.54 \%)$ children in the present study did not adhere to their respective antiepileptic regimens. Qoul et al reported high adherence in $29.4 \%$ of their paediatric study population ${ }^{21}$. Though Nazziwa et al reported adherence in $79.5 \%$ children by self-reporting, this high percentage dropped down to $22.1 \%$ when correlated with serum drug levels ${ }^{22}$. Asadi-Pooya AA reported satisfactory drug compliance among $72.4 \%$ of study patients which comprised of both adolescents and children $^{18}$. Non adherence may be the most important cause of poorly controlled epilepsy ${ }^{23}$. Seventy percent of patients reported antiepileptic drug omission ${ }^{5}$. Non adherence rates ranging from $12 \%$ to as high as $64 \%$ have been reported in earlier studies conducted among adolescents and/or adults $^{5,24,25}$. As greater than $95 \%$ adherence may be needed to adequately suppress the epileptic seizures, missing a dose or two weekly may suffice to cause failure of therapy and trigger seizures ${ }^{26}$. Thus, epileptic patients should be classified as either adherent or non-adherent ${ }^{23}$. Classifying patients as having high, moderate and low adherence should be discouraged. Hence, in the present study while high adherence score was classified as adherent, moderate and low adherence score on MMAS were clubbed as non-adherent as reported earlier ${ }^{5}$.

Despite India being a male dominant society, our study revealed no statistical significant difference among genders for their number, age, duration of epilepsy, mean family members, seizure frequency and adherence rates. This is agreement with studies by Gabr et $a l^{23}$, Johnbull et $a l^{26}$ and Liu et $a l^{27}$. In the present study medication adherence was significantly and adversely affected by increasing age of children and duration of epilepsy. Kyngas et al reported that compliance of adolescents with epilepsy for 1-3 years was greater than the compliance of adolescents with epilepsy for more than three years ${ }^{28}$. However, the same study ruled out age of the patient as an independent factor significantly associated with compliance ${ }^{28}$. Other studies failed to report any similar association $^{17,22,23}$. Our present study and studies by Asadi-Pooya $\mathrm{AA}^{17}$ and Gabr et a ${ }^{23}$ demonstrate that a positive family history is significantly associated with non-adherence. Though Kyngas et $a l^{28}$ refute any effect of family size on adherence to anti-epileptics, Asadi-Pooya $\mathrm{AA}^{17}$ and Gabr et $a l^{23}$ support our findings that increasing family size has a negative role on medication adherence.
In the present study, adherence to AED was adversely affected if one or more seizures occurred in the last 3 months compared to children who had no seizures in the last 3 months. Similar findings were reported by Gabr et $a l^{23}$. Kyngas et al reported that adherence was adversely affected if seizures occurred daily compared to less than weekly $^{28}$. In our study, there was no correlation between adherence and seizure frequency. In our study, the number of tablets ingested was not significantly associated with adherence to AEDs. This was similar to findings in studies by AsaadiPooya et $a l^{17}$, Sweileh et $a l^{5}$ and Jones et $a l^{25}$ but contrary to studies by Kyngas et $a l^{28}$ and Gabr et $a l^{23}$.

The present study showed that children were more likely to be adherent to AEDs if all the AEDs were given at the same time, i.e. once a day, even if more than one AED was used. Asadi-Pooya AA found that patients prescribed a nocturnal dose of phenobarbitone were more compliant than those prescribed carbamazepine or valproic acid twice or thrice daily ${ }^{17}$. Chances of non-adherence increased if the immediate caregiver was employed. Nazziwa et al has reported increased likelihood of noncompliance in a child if caregiver had an occupation $^{22}$. Gender of caregiver was not differentiated in the present study as all the caregivers were females, either mother or grandmother.

Our study demonstrates that satisfaction scores were higher in medication adherent children, particularly in the effectiveness, convenience and global satisfaction domains but not in the side effects domain. In other words, if patients are more satisfied with the treatment then they are more likely to adhere to the medication regimen. Patients on one drug demonstrated significantly more satisfaction in the effectiveness and convenience domains compared with patients on two or more drugs. Patients on monotherapy find it more convenient to take a single medicine. Sweileh et al also reported greater satisfaction in the effectiveness domain among adolescents receiving monotherapy ${ }^{5}$. However, the overall global satisfaction scores were not significantly different and this supports our findings that the adherence status of epileptic children was not affected by the number of drugs.

There are some limitations in this study. This is a single centre study and hence the results cannot be extrapolated to other geographical areas. Our hospital is a tertiary care referral centre for the nearby region of approximately $100 \mathrm{~km}$ radius. Hence, patients usually have 'difficult to treat' or 'refractory' diseases. Though the translated version of MMAS used in the present study was checked 
and found to have an acceptable internal consistency, the Hindi translated and validated version of the same is not available. We relied on interviews with caregivers to measure adherence and this may be inaccurate and biased. Self-report on medication adherence is prone to recall bias and respondents usually overestimate adherence ${ }^{17}$. Serum AED estimation could not be done due to financial constraints. However, single essay for blood drug levels may not reflect variations in drug levels by the day and hence is not acceptable as a full-proof method for medication adherence studies $^{22}$. Further research is warranted to ascertain the specific adherence barriers pertaining to epileptic children from this part of the world.

\section{Conclusions}

- Twenty nine percent of epileptic children showed medication adherence to AEDs in the present study.

- Increasing age of children, increased duration of epilepsy, increasing mean number of family members, patients taking medications more than once per day and employed caregiver status were significantly associated with nonadherence in epileptic children.

- Satisfaction scores were higher in medication adherent children, in the effectiveness, convenience and global satisfaction domains but not in the side effects domain.

\section{References}

1. Raina SK, Razdan S, Nanda R. Prevalence of neurological disorders in children less than 10 years of age in RS Pura town of Jammu and Kashmir. Journal of Pediatric Neurosciences 2011; 6:103-5. https://doi.org/10.4103/1817-1745.92815 PMid: 22408654 PMCid: PMC3296399

2. Kvalsunda MP, Birbeckb GL. Epilepsy care challenges in developing countries. Current Opinion in Neurology 2012; 25:179-86.

https://doi.org/10.1097/WCO.0b013e3283 50 baf8

PMid: 22322413

3. Cramer JA, Glassman M, Rienzi V. The relationship between poor medication compliance and seizures. Epilepsy and Behaviour 2002; 3:338-42.

https://doi.org/10.1016/S15255050(02)000 37-9
4. Dimatteo MR. The role of effective communication with children and their families in fostering adherence to pediatric regimens. Patient Education and Counselling 2004; 55(3):339-44. https://doi.org/10.1016/j.pec.2003.04.003 PMid: 15582339

5. Sweileh WM, Ihbesheh MS, Jarar IS, Taha AS, Sawalha AF, Zyoud SH, et al. Selfreported medication adherence and treatment satisfaction in patients with epilepsy. Epilepsy and Behaviour 2011; 21(3):301-5.

https://doi.org/10.1016/j.yebeh.2011.04.01 1

PMid: 21576040

6. Atkinson MJ, Kumar R, Cappelleri JC, Hass SL. Hierarchical construct validity of the treatment satisfaction questionnaire for medication (TSQM version II) among outpatient pharmacy consumers. Value in Health 2005; 8(Suppl 1):S9-S24.

https://doi.org/10.1111/j.15244733.2005.0 0066.x

PMid: 16336491

7. Zyoud SH, Al-Jabi SW, Sweileh WM, Morisky DE. Relationship of treatment satisfaction to medication adherence: findings from a cross-sectional survey among hypertensive patients in Palestine. Health and Quality of Life Outcomes 2013; 11:191.

https://doi.org/10.1186/1477-7525-11-191

PMid: 24195638 PMCid: PMC4228307

8. Morisky DE, Ang A, Krousel-Wood M, Ward HJ. Predictive validity of a medication adherence measure in an outpatient setting. The Journal of Clinical Hypertension 2008; 10:348-54. https://doi.org/10.1111/j.17517176.2008.07572.x

PMid: 18453793 PMCid: PMC2562622

9. Furue M, Onozuka D, Takeuchi S, Murota $\mathrm{H}$, Sugaya M, Masuda $\mathrm{K}$ et al. Poor adherence to oral and topical medication in 3096 dermatological patients assessed by the Morisky Medication Adherence Scale-8. British Journal of Dermatology 2015; 172:272-5.

https://doi.org/10.1111/bjd.13377

PMid: 25154923 PMCid: PMC4303916

10. Nagarkar AM, Gadhave SA, Sharma I, Choure A, Morisky D. Factors influencing medication adherence among hypertensive 
patients in a tertiary care hospital, Pune, Maharashtra. National Journal of Community Medicine 2013; 4:559-63.

11. Bharmal M, Payne K, Atkinson MJ, Desrosiers MP, Morisky DE, Gemmen E. Validation of an abbreviated Treatment Satisfaction Questionnaire for Medication (TSQM-9) among patients on antihypertensive medications. Health and Quality of Life Outcomes 2009; 7:36. https://doi.org/10.1186/1477-7525-7-36 PMid: 19397800 PMCid: PMC2678998

12. Atkinson MJ, Sinha A, Hass SL, et al. Validation of a general measure of treatment satisfaction, the Treatment Satisfaction Questionnaire for Medication (TSQM), using a national panel study of chronic disease. Health and Quality of Life Outcomes 2004; 2:12.

https://doi.org/10.1186/1477-7525-2-12

13. Amudhan S, Gururaj G, Satishchandra P. Epilepsy in India I: Epidemiology and public health. Annals of Indian Academy of Neurology 2015; 18:263-77.

https://doi.org/10.4103/0972-2327.160093 PMid: 26425001 PMCid: PMC4564458

14. Mani KS, Rangan G, Srinivas HV, Kalyanasundaram S, Narendran S, Reddy AK. The Yelandur study: A communitybased approach to epilepsy in rural South India--epidemiological aspects. Seizure 1998; 7:281-8.

https://doi.org/10.1016/S10591311(98)800 19-8

15. Banerjee TK, Hazra A, Biswas A, Ray J, Roy $\mathrm{T}$, Raut DK, et al. Neurological disorders in children and adolescents. Indian Journal of Pediatrics 2009; 76:139-46.

https://doi.org/10.1007/s12098-008-0226-

PMid: 19082533

16. Udani V. Paediatric epilepsy-An Indian perspective. Indian Journal of Pediatrics 2005; 72(4):309-13.

https://doi.org/10.1007/BF02724012

17. Asadi-Pooya AA. Drug compliance of children and adolescents with epilepsy. Seizure 2005; 14(6):393-5.

https://doi.org/10.1016/j.seizure.2005.05.0 03

PMid: 15978849
18. Bhatt KM, Malhotra SD, Patel KP, Patel VJ. Drug utilization in paediatric neurology outpatient department: A prospective study at a tertiary care teaching hospital. Journal of Basic and Clinical Pharmacy 2014; 5:68-73.

https://doi.org/10.4103/0976-0105.139729 PMid: 25278669 PMCid: PMC4160722

19. Newale S, Bachani DS. Demographic characteristics of epilepsy patients and antiepileptic drug utilization in adult patients: Results of a cross-sectional survey. Neurology India 2016; 64:1180-6. https://doi.org/10.4103/0028-3886.193806 PMid: 27841183

20. Mistry RA, Solanki KC, Prajapati HK, Doshi TM, Trivedi HR. Drug utilization pattern of anti-seizure drugs and their adverse effects in the paediatric population, in a tertiary care hospital attached to a medical college. International Journal of Basic and Clinical Pharmacology 2014; 3:336-42. https://doi.org/10.5455/23192003.ijbcp201 40415

21. Qoul KZ, Qasem DA, Samawi OH, Matter LN, Abo-tineh SI, Abo-olem M. Antiepileptic medication adherence in children with epilepsy at Queen Rania AlAbdullah Children Hospital. Indian Journal of Medical Research and Pharmaceutical Sciences 2015; 2(10):1623.

22. Nazziwa R, Mwesige AK, Obua C, Ssenkusu JM, Mworozi E. Adherence to antiepileptic drugs among children attending a tertiary health unit in a low resource setting. Pan African Medical Journal 2014; 17:44.

https://doi.org/10.11604/pamj.2014.17.44. 3399

PMid: 25018794 PMCid: PMC4085948

23. Gabr WM, Shams ME. Adherence to medication among outpatient adolescents with epilepsy. Saudi Pharmaceutical Journal 2015; 23(1):33-40. https://doi.org/10.1016/j.jsps.2014.05.003 PMid: 25685041 PMCid: PMC431101

24. McAuley JW, McFadden LS, Elliott JO, Shneker BF. An evaluation of selfmanagement behaviours and medication adherence in patients with epilepsy. Epilepsy and Behaviour 2008; 13:637-41. 
https://doi.org/10.1016/j.yebeh.2008.07.00 5

PMid: 18656553

25. Jones RM, Butler JA, Thomas VA, Peveler RC, Prevett M. Adherence to treatment in patients with epilepsy: associations with seizure control and illness beliefs. Seizure 2006; 15:504-8. https://doi.org/10.1016/j.seizure.2006.06.0 03

PMid: 16861012

26. Johnbull O, Farounb B., Adeleye A., Uche A. Evaluation of factors influencing medication adherence in patients with epilepsy in rural communities of Kaduna State, Nigeria. Neuroscience and Medicine 2011; 2(4):299-305.

https://doi.org/10.4236/nm.2011.24039
27. Liu J, Liu Z, Ding H., Yang X. Adherence to treatment and influencing factors in a sample of Chinese epilepsy patients. Epileptic Disorders 2013; 15:289-94. PMid: 23906632

28. Kyngas H. Compliance with health regimens of adolescents with epilepsy. Seizure 2000; 9:598-604.

https://doi.org/10.1053/seiz.2000.0470 PMid: 11162760 